05

\title{
Влияние температуры на ромбическую форму молекулярных кристаллов парацетамола
}

\author{
(C) А.П. Беляев, ${ }^{1}$ В.П. Рубец, ${ }^{2}$ В.В. Антипов ${ }^{1}$ \\ ${ }^{1}$ Санкт-Петербургская государственная химико-фрармацевтическая академия, \\ 197376 Санкт-Петербург, Россия \\ ${ }^{2}$ Санкт-Петербургский государственный технологический институт (технический университет), \\ 190013 Санкт-Петербург, Россия \\ e-mail: Alexei.Belyaev@pharminnotech.com
}

(Поступило в Редакцию 7 июля 2016 г.)

Методом дифференциальной сканирующей калориметрии исследовано влияние нагревания на ромбическую форму молекулярных кристаллов парацетамола. Установлено, что молекулярные кристаллы парацетамола ромбической формы, полученные при вакуумном синтезе парацетамола из паровой фазы в результате сложного превращения, включающего переход второго рода, протекающий с образованием некой „предпереходной фазы“, содержат зародыши моноклинной формы, способствующие полиморфному превращению формы II в форму I при нагревании.

DOI: 10.21883/JTF.2017.04.44327.1977

\section{Введение}

Парацетамол (N-(4-гидроксифенил) ацетамид) благодаря своим свойствам представляет интерес как для разработки различных практических приложений, так и для фундаментальных исследований. О его популярности свидетельствует хотя бы тот факт, что, согласно информационной системе SCOHUS, только в 2016 г. исследованиям свойств парацетамола и способам его получения было посвящено более сотни научных публикаций (см., например, [1-5]). Парацетамол может кристаллизоваться в трех различных полиморфных формах, известных как формы I, II и III [6]. Форма I (молекулярный кристалл моноклинной модификации) является стабильной при естественных условиях. Однако она характеризуется низкой технологичностью, ей присуща сыпучесть, плохое смачивание и плохое растворение. Форма II (молекулярный кристалл ромбической модификации) легко подвергается пластической деформации, подходит для прямого прессования, но является метастабильной. Форма III крайне неустойчива и поэтому ее кристаллическая структура пока достоверно не определена. Молекулярные кристаллы ромбической модификации получают, как правило, из растворов [7-18]. Нам удалось синтезировать кристаллы ромбической модификации путем вакуумной сублимации порошка кристаллов моноклинной модификации $[19,20]$. В настоящей работе представлены результаты исследования устойчивости полученных кристаллов.

\section{Эксперимент}

Модельные объекты синтезировались путем вакуумного термического испарения порошка парацетамола, состоящего из кристаллов моноклинной сингонии, с последующей конденсацией на медную подложку согласно методике $[19,20]$. Тепловые свойства изучались в специальной калориметрической ячейке (модифицированный аналог DSC-2). Кривые дифференциальной сканирующей калориметрии (ДСК) были записаны при нагревании образцов в атмосфере азота при нормальном давлении от комнатной температуры до температуры $460 \mathrm{~K}$. Скорость нагрева составляла $10 \mathrm{~K} / \mathrm{min}$. Структурные исследования проводились на дифрактометре ДРОН-4 и оптическом микроскопе МБС-10.

\section{Результаты и их обсуждение}

Исследовалось влияние нагрева на молекулярные кристаллы парацетамола ромбической формы, спектр дифракции рентгеновских лучей которых демонстрирует рис. 1.

На рис. 2. представлены кривые ДСК. Рис. 2, a соответствует нагреву исходного образца, а рис. $2, b-$ образцу, полученному после нагрева и охлаждения до комнатной температуры. При нагреве исходного образца на кривой ДСК регистрировалось два эндотермических пика. Первый пик соответствовал температуре $415 \mathrm{~K}$, а второй - температуре $442 \mathrm{~K}$. На кривой ДСК, снятой

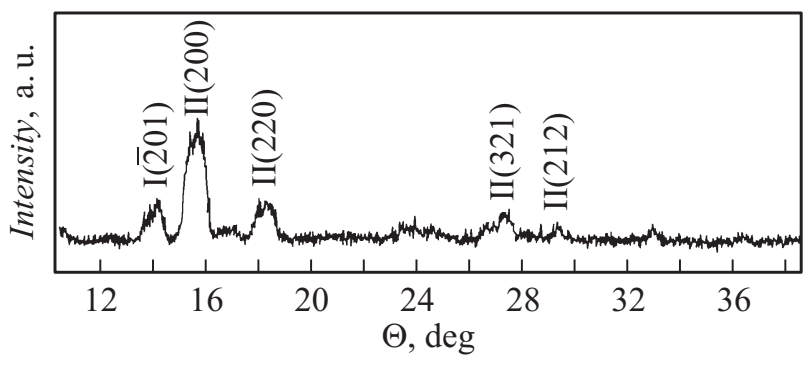

Рис. 1. Спектр дифракции рентгеновских лучей исходного образца молекулярных кристаллов парацетамола. 


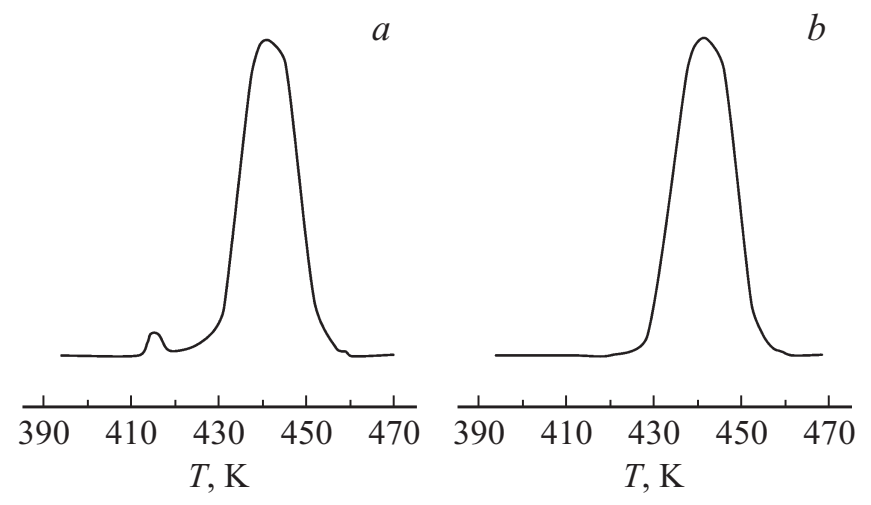

Рис. 2. Кривые ДСК, полученные при нагревании исходного $(a)$ и подвергнутого нагреву $(b)$ образцов парацетамола.

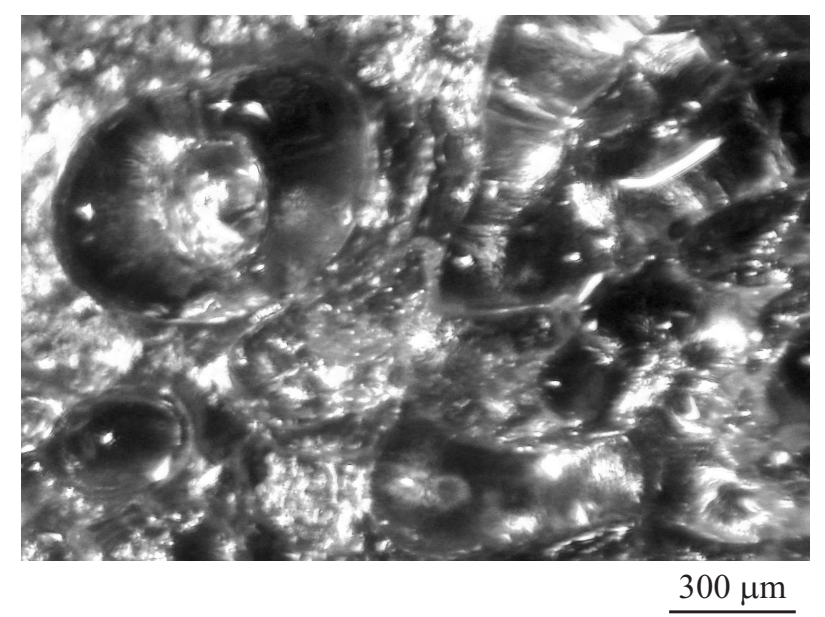

Рис. 3. Микрофотография исходного образца парацетамола, нагретого до температуры $435 \mathrm{~K}$.

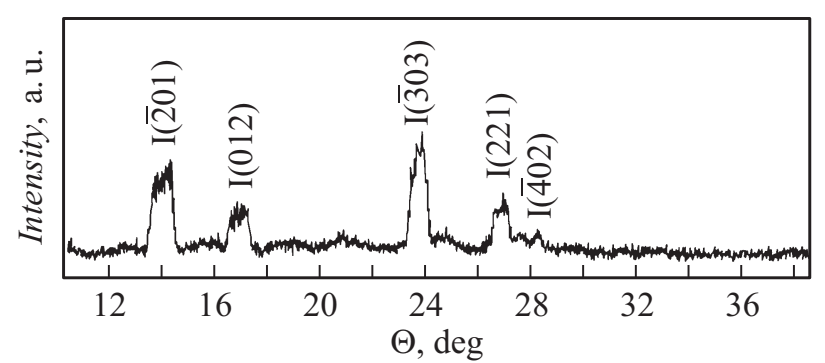

Pис. 4. Спектр дифракции рентгеновских лучей образца парацетамола, подвергнутого нагреванию.

после нагрева (рис. 2,b), низкотемпературный пик не регистрировался. При температуре $442 \mathrm{~K}$ происходило плавление образца. Об этом свидетельствует микрофотография, представленная на рис. 3. Температура плавления оказалась равной температуре плавления моноклинной формы кристаллов, что позволило предположить, что при температуре, соответствующей первому пику на кривой ДСК (рис. 2,a), происходило полиморфное превращение из формы II в форму I.
Предположение подтверждается спектром дифракции рентгеновских лучей образца после его нагрева (рис. 4). Причиной относительно низкой температуры полиморфного превращения может быть недостаточная чистота формы II. Как можно видеть из спектра рентгеновских лучей исходного материала (рис. 1), в нем присутствуют рефлексы, характерные для моноклинной формы (плоскость $(\overline{2} 01))$. Можно предположить, что им отвечают „примеси“, оставшиеся в результате неполного фазового превращения исходного материала в форму II. В [20] было показано, что формирование исследуемых образов формы II осуществляется сложным образом в виде суперпозиции двух фазовых переходов: перехода первого рода с изменением плотности и переходом второго рода с изменением упорядоченности. Переход второго рода протекает в виде размытого фазового перехода с образованием некой ,предпереходной фазы“, необратимо расходуемой в процессе фазового превращения, результатом которого являются кристаллы ромбической сингонии. Очевидно, остатки предпереходной фазы играют роль зародышей моноклинной формы, способствующих переходу формы II в форму I при нагревании.

\section{Заключение}

Представленные результаты позволяют констатировать, что молекулярные кристаллы парацетамола ромбической формы, полученные при вакуумном синтезе парацетамола из паровой фазы в результате сложного превращения, включающего переход второго рода, протекающего с образованием некой предпереходной фазы, содержат зародыши моноклинной формы, способствующие полиморфному превращению формы II в форму I при нагревании.

\section{Список литературы}

[1] Kalmbate P.K., Srivastava A.K. // Sensor. Actuator. B: Chem. 2016. Vol. 233. N 10. P. 237-244.

[2] Bounbi I., Mokhnachi N.B., Haddadine N., Barille R. // J. Drug Deliv. Sci. Technol. 2016. Vol. 33. N 6. P. 58-65.

[3] Hacene Y.C., Singh A., van Den Vooter G. // Intern. J. Pharmac. 2016. Vol. 506. N 6. P. 138-147.

[4] Sarkar A., Pandit B.R., Sinha B. // J. Chem. Thermodynam. 2016. Vol. 96. N 5. P. 161-168.

[5] Viana R.B., Ribeiro G.I.O., Santos S.F.F., Quintero D.F., Viana A.B., Da Silva A.B.F., Moreno-Fuquen // Spectrochim. Acta. A: Molecul. Biomolecul. Spectr. 2016. Vol. 162. N 6. P. $16-26$

[6] Giordano F., Rossi A., Savioli A. // J. Therm. Analys. Colorimetr. 2002. Vol. 68. P. 575-590.

[7] Nanubolu J.B., Burley J.C. // Molec. pharmaceut. 2012. Vol. 9. N 6. P. $1544-1558$.

[8] Myrick M.L., Baranowski M., Profeta L.T.M. // J. Chem. Educat. 2010. Vol. 87. N 8. P. 842-844.

[9] Delmas T., Shah U.V., Roberts M.M., Williams D.R., Heng J.Y.Y. // Powder Technol. 2013. Vol. 236. P. 24-29. 
[10] Perrin M.A., Elmaleh H., Zaske L., Neumann M.A. // Chem. Communicat. 2009. N 22. P. 3181-3183.

[11] Anuar M.S., Briscoe B.J. // Drug Development and Pharmacy. 2010. Vol. 36. N 8. P. 972-979.

[12] Picciochi R., Diogo H.P., Minas Da Piedade M.E. // J. Therm. Analys. Calorim. 2010. Vol. 100. N 2. P. 391-401.

[13] Profio G. Di, Tucci S., Curcio E., Drioli E. // Chem. Mater. 2007. Vol. 19. N 10. P. 2386-2388.

[14] Capes J.S., Cameron R.E. // Cryst. Growth Des. 2006. Vol. 7. N 1. P. $108-112$.

[15] Thomas L.H., Wales C., Zhao L., Wilson C.C. // Cryst. Growth Des. 2011. Vol. 11. N 5. P. 1450-1452.

[16] Price C.P., Grzesiak A.L., Matzger A.J. // J. Am. Chem. Soc. 2005. Vol. 127. N 15. P. 5512-5517.

[17] Chadwick K., Myerson A., Trout B. // Cryst. Eng. Comm. 2011. Vol. 13. N 22. P. 6625-6627.

[18] Lang M., Grzesiak A.L., Matzger A.J. // J. Am. Chem. Soc. 2002. Vol. 124. N 50. P. 14834-14835.

[19] Беляев А.П., Рубеи, В.П., Антипов В.В., Бордей Н.С., Зарембо В.И // ЖТФ. 2014. Т. 84. Вып. 3. С. 141-143.

[20] Беляев А.П., Рубеи, В.П., Антипов В.В., Бордей Н.С. // ЖТФ. 2014. Т. 84. Вып. 7. С. 156-158. 